\title{
Elektronik Dergilerin Üniversite Kütüphanelerine Ekonomik Etkisi: İran Temel Bilimler İleri Araştırmalar Enstitüsü Kütüphanesi Örneği*
}

\section{The Economic Impact of Electronic Journals on University Libraries: The Case of Iranian Institute for Advanced Studies in Basic Sciences (IASBS)}

\section{Mehdi Afzali ${ }^{\star \star}$}

Öz

Bu makalede Iran Temel Bilimler Ileri Araştırmalar Enstitüsü (TBIAE) Kütüphanesi'nde dergilerin basılı kopyaları yerine elektronik sürümlerine erişim sağlamanın Kütüphanenin karşı karşıya kaldığı bütçe ve yer sorunlarına çözüm getirip getirmediği sorusuna yanıt aranmaktadır. Bunun için TBIAE Kütüphanesi'nde 2002'de abone olunan 155 derginin basılı ve elektronik sürümlerine yapılan harcamalar (abonelik giderleri, posta harcamaları, denetim giderleri, ciltleme ve arşivleme harcamaları) karşılaştırılmıştır. Sonuçta, TBIAE Kütüphanesi 2002'de abone olunan basılı dergiler yerine aynı dergilerin elektronik sürümlerine abone olsaydı toplam harcamaların azalabileceği ortaya çıkmıştır. Bu rakam TBIAE Kütüphanesi'nin bütçesinde yaklaşık \%13'lük tasarruf etmek anlamına gelmektedir.

Anahtar sözcükler: Elektronik dergiler, Koleksiyon yönetimi, Bilgi ekonomisi, Üniversite kütüphaneleri - Iran.

\footnotetext{
Abstract

The objective of this study is to answer the following conjecture: If Iranian Institute for Advanced Studies in Basic Sciences (IASBS)

* Bu makale, yazarın bilim uzmanlığı tezine (Afzali, 2003) dayanmaktadır.

${ }^{* *}$ H.Ü. Bilgi ve Belge Yönetim Bölümü Doktora Öğrencisi ve TBIAE Kütüphanesi Müdür Yardımcısı (afzali@hacettepe.edu.tr).
} 
Library subscribed to the electronic versions of journals instead of their printed copies, its budget and space problems would be eased. To prove this hypothesis we compared various expenditures (subscriptions, mailing, control, binding and archiving) of both printed and electronic versions of journals that IASBS Library subscribed to in 2002. We found that if IASBS Library had subscribed to the electronic versions of journals instead of their printed equivalents, the Library would have decreased the total expenditures in its overall material acquisition budget by $13 \%$.

Keywords: Electronic journals, Collection management, Economics of information, University Libraries - Iran.

\section{Giriş}

Kütüphane, üniversitedeki eğitim-öğretim için uygun bir koleksiyona sahip olmalıdır. Kütüphanenin iyi bir şekilde hizmet vermesi koleksiyondaki kaynakların çok sayıda olması ya da çok pahalı olması anlamına gelmez. Ancak son zamanlarda kütüphaneler, kaynak türlerinden biri olan süreli yayınların gittikçe artan fiyatları ve bilgi birikimi karşısında azalan veya değişmeyen bütçeleri nedeniyle büyük zorluklarla karşılaşmaktadırlar (Schmidt, 1999, s. 495).

Kütüphanelerin koleksiyon geliştirmesini en fazla etkileyen konu kütüphanelerin bütçesidir. Kullanıcıların çeşitli bilgi isteklerinin karşılanabilmesi için kütüphanenin yeterince bütçesi olması gerekmektedir. Bilgi kaynaklarının fiyat artışı günümüzde birçok üniversite kütüphanesini satın alma yoluyla sağladıkları kaynakları sınırlandırmaya zorlamaktadır (Çakın, 1998, s. 52). Bütçe problemi sadece Türkiye'de değil, tüm dünyada üniversite kütüphanelerinin karşı karşıya kaldığı evrensel bir problemdir. Bununla birlikte yayın sayısının hızla artması, bilim ve teknik alanda uzmanlaşma, kaynakların fiyat artışı, bilgi teknolojilerindeki gelişmeler, elektronik yayıncılığa geçiş, vs. gibi nedenler karşısında, günümüzün diğer kurumları gibi, üniversite kütüphaneleri de büyümekte, sağladıkları hizmetlerin çeşit ve sayısı artmaktadır. Bu durum kütüphaneleri mali bir ikilemle karşı karşıya getirmiştir. Şu anda kütüphanelerin bütçelerinin büyük kısmı, yer kapasitenin artırılması ile ilgili olarak bina ve raflara harcanmaktadır. Oysaki elektronik kaynaklar basılı kaynakla- 
ra oranla daha az yer kaplamakta, depolama, iletişim ve erişim teknolojilerinin maliyeti de sürekli düşmektedir. Elektronik kaynaklara sahip kütüphaneler ya da kuruluşlar bu kaynakları, zamandan ve mekândan bağımsız olarak kullanıcıların erişimine sunabilmektedirler.

Pahalı ve nadiren kullanılan dergiler kütüphane bütçesinin önemli bir kısmını götürmektedir (Tinerella, 1999). Ekonomik sıkıntı altında olan kütüphaneler, artan abonelik ücretleri ve bütçelerdeki yetersizlikler sonucunda, koleksiyonlarındaki bir kısım dergileri iptal etmek zorundadırlar. Kütüphanelerin dergi aboneliklerinin iptali karşısında aldıkları önlem, genelde belge sağlama olarak adlandırılan ve okuyucuya istediği makaleyi getirmeye yönelik bir işlemdir. Bu amaçla kütüphaneler diğer kütüphanelerle işbirliğine giderek karşılıklı belge temin etmektedirler. Kütüphanelerarası ödünç verme, belge sağlama ve ortak koleksiyon geliştirme işbirliğinin en yaygın örnekleridir. Ancak özellikle basılı kaynağa dayalı bu modelin uzun sürede hiç de ekonomik olmadığı görüşü hakimdir. 1970'li yıllardan itibaren dergilerin yükselen fiyatları ile birlikte kütüphaneler ekonomik sıkıntılarla karşı karşıya kalmışlardır. Basılı kaynaklara dayalı kütüphane koleksiyonların artış hızının düşmesi beklenmektedir. Bunun nedenleri kütüphanelerin karşılaştığı ekonomik sıkıntılar, elektronik kaynakların giderek artan payı ve kaynak paylaşımının ön plana çıkmasıdır.

1990'ların sonundan itibaren elektronik bilgi kaynaklarına ilgi çoğalmıştır. Istatistiklere göre 1997-1998 yıllarında Amerikan Araştırma Kütüphaneleri Derneğinin (ARL) üyesi olan kütüphanelerin \%29'u ve ARL üyesi olmayan kütüphanelerin \%34'ü basılı dergileri iptal ederek elektronik dergilerden yararlanma yoluna gitmişlerdir (Montgomery ve Sparks, 2000).

Piyasada bulunan elektronik dergilere ise genellikle CD-ROM, çevrimiçi veya ağ aracılığıyla erişmek mümkündür. Elektronik yayınlara genellikle üç yoldan erişilebilir: (Stange, 1999).

- Bedava elektronik dergiler: Bedava dergilere web ortamında erişim için değişik modeller denenmektedir: a) Web ortamında herkese açık bedava tam metin erişime olanak sağlayan elektronik dergiler. b) Bedava sınırlı içeriğe (örneğin, özet) erişim sağlayan dergiler. c) Güncel bilgi duyurusu gibi belirli hizmetlerle desteklenen ve tam metinlerine erişilebilen dergiler. 
- Yıllık olarak abone olunan elektronik dergiler: Yayıncılık dünyasında dergilere yıllık olarak abone olmak yaygın ve basit bir ödeme şeklidir. Elektronik dergilerin abonelik ücretleri temel olarak tek abonelik ücreti veya paket olarak belirlenmektedir.

- Parça başı ücret ödenen elektronik dergiler: Kütüphaneciler elektronik kaynaklar koleksiyonu geliştirirken "satın alma" ya da "kiralama" ikilemiyle karşı karşıya kalmaktadırlar. Birçok kütüphaneci ve bilim insanı yayınevlerinin "gördüğün kadar öde" (pay-per-view) modeliyle ilgilenmekte ve birçok kütüphane bu tür modellerin kullanılmasını tercih etmektedir. Böylece kütüphaneler az kullanılan dergilere abone olmak yerine yayınevlerinin ya da ticari elektronik belge sağlama şirketlerinin hizmetlerinden yararlanmaktadırlar (Kiernan, 1998; Odlyzko, 1999).

Elektronik dergilerin sayısının çoğalmasıyla birlikte üniversite kütüphanelerinde bu tür kaynaklara önem verilmiş, dolayısıyla da kullanıcı istekleri de çoğalmıştır. Örneğin, 1998'de Almanya'daki Northrhine-Westfalia (NRW) konsorsiyumunun üyeleri iki büyük yayınevi (Springer ve Elsevier) tarafından yayınlanan dergilere abone olurken, dergilerin elektronik sürümlerine istek sadece \%26 idi. Ancak 2002'de bu oran \%72'ye yükselmiştir (Obst, 2003, s. 23).

Drexel Üniversitesi W. Hagerty Kütüphanesinde basılı dergi sayısı 1998'de 1710, elektronik dergi sayısı 200 iken 2003'de basılı dergi sayısı 375'e düşmüş ve elektronik dergi sayısı ise 12,000'a yükselmiştir. Bu kütüphanede basılı dergi sayısının azalmasının nedeni, elektronik dergilerin personel ve harcamaların azalmasında etkisi olması aynı zamanda bu kütüphanenin diğer kütüphaneler için bir model olarak kullanılmasıdır. Bir diğer araştırmaya göre Drexel Üniversitesinde çalışan öğretim üyelerinin kullandığı kaynakların \%70'i elektronik dergilerden ibarettir. Bu oran doktora öğrencileri arasında \%77'e kadar yükselmektedir (Montgomery, 2000; Montgomery ve King, 2003).

Gelişmiş ülkelerde özellikle 1980'lerden itibaren basılı ve elektronik bilgi kaynaklarıyla ilgili yapılmış pek çok çalışmaya rastlamak mümkündür. Loughborough Üniversitesindeki basılı ve elektronik koleksiyon ile ilgili bir maliyet-yarar analizi yapılmıştır. Bu çalışmada basılı ve elektronik koleksiyonlar pek çok açıdan karşılaştırılmış ve elektronik koleksiyonun daha pahalı 
olduğu görülmüştür. Ancak elektronik koleksiyonun yararlarının daha çok olduğu ve bu maliyeti karşılayacağı sonucuna varılmıştır (Gadd, 1998).

W. Hagerty Kütüphanesi, 1998'de Kütüphane ve Müze Hizmetleri Enstitüsü (Institute for Museum and Library Services-IMLS) tarafından elektronik dergilerin ekonomik etkisini araştırmak için bir model olarak seçilmiştir ve Amerika'daki üniversite kütüphaneleri içinde ilk örnektir (Montgomery ve Bielec 2000). Montgomery ve Sparks'ın (2000) çalışmasında ise bu kütüphanede, basılı dergi koleksiyonundan elektronik dergi koleksiyonuna geçişin işçilik ve diğer maliyetler üzerinde yarattığı (özellikle ekonomik) etkiler incelenmiştir. Çalışmanın genelinde ise elektronik dergilerin harcamaları artırdığı görülse de iyi bir seçim olduğu kabul görmüştür.

Elektronik ve basılı kaynakların fiyatlarını karşılaştırdığımızda büyük bir farklıı̆̆ın olduğunu görmekteyiz. Elektronik kaynaklar özellikle elektronik dergilerin fiyatları ve fiyat politikaları hararetli bir konu olarak birçok araştırmacı tarafından tartışılmaktadır. Bu konuda son araştırmalardan birisi Cox (2003) tarafından Emerald Yayınevinin dergileri üzerinde yapılmıştır. Bu araştırmada bu iki yayınevi tarafından yayınlanan dergilerin basılı ve elektronik sürümlerinin 2002'deki abonelik ücretleri karşılaştırılmıştır. Emerald Yayınevi tarafından yayınlanan dergilerin basılı ve elektronik sürümlerinin fiyatı her bir dergi için 3849 dolar hesaplanmıştır. Ancak bu dergilerin elektronik sürümleri ortalama her bir dergi için 218 dolar olarak belirlenmiştir. Bu durumda basılı sürümlerin her makalesi 108 dolar ve elektronik dergilerin her makalesi 6 dolar olarak hesaplanmıştır (Cox, 2003, ss. 83-84).

Kütüphanelerin ilgisini çeken bir diğer konu ise, her kullanımın fiyatı (Cost per Reading-CPR) ve bir makalenin maliyeti (Cost per Articles-CPA) veya makale başına yapılan harcamalardır. Bu konudaki araştırmalardan birisi Obst (2003) tarafından Northrhine- Westfalia (NRW) konsorsiyumu üyelerinin 2001'de abone oldukları dergiler üzerinde yapılmıştır. Bu araştırmanın sonuçlarına göre basılı dergilerde her makalenin kullanım maliyeti 19 dolar olurken bu miktar elektronik dergilerde 3 dolar olarak hesaplanmıştır (Obst, 2003, s. 30).

Drexel Üniversitesi W. Hagerty Kütüphanesinde 2002'de her bir elektronik dergiye ortalama 147 dolar ödenmiştir. Drexel projesinde ilk grup olarak tek 
tek abone olunan elektronik dergilerin abonelik ücreti 432 dolar olarak belirlenmiştir. İkinci grup yayınevleri ve aracı şirketlerin elektronik dergi paketleri veya konsorsiyum şeklinde satın alınmaktadır (Örneğin, ScienceDirect, Kluwer gibi). Bu grubun abonelik ücreti ortalama 134 dolardır. Üçüncü grup ise aracı firmalar (aggregator) tarafından pazarlanan dergilerdir. Bunlar farklı yayınevleri tarafından yayınlanan çeşitli dergilerden bir araya getirilmiştir. Drexel Üniversitesi Kütüphanesinde abone olunan elektronik dergiler içinde bu gruptakiler en ucuz olanlardır (fiyatı 60 dolar). Basılı dergilere ödenen miktar 100 dolar olarak hesaplanmıştır (Holmström, 2004) (Bkz. Tablo 1).

Tablo 1: 2002'de Drexel Projesinde Her Makalenin Kullanım Fiyatı

\begin{tabular}{lrrrrrr}
\hline Dergi türü & $\begin{array}{r}\text { Abonelik } \\
\text { ücreti }(\$)\end{array}$ & $\begin{array}{r}\text { Her bir } \\
\text { derginin } \\
\text { fiyatı }(\$)\end{array}$ & $\begin{array}{r}\text { Kullanma } \\
\text { sayısı }(\$)\end{array}$ & $\begin{array}{r}\text { Her bir } \\
\text { kullanımın } \\
\text { abonelik } \\
\text { ücreti }(\$)\end{array}$ & $\begin{array}{r}\text { Her bir } \\
\text { kullanımın } \\
\text { işlem fiyatı } \\
(\$)\end{array}$ & $\begin{array}{r}\text { Toplam } \\
\text { kullanım bir } \\
\text { fiyatı }(\$)\end{array}$ \\
\hline $\begin{array}{l}\text { Elektronik dergiler } \\
\text { Tek tek aboneler }\end{array}$ & 73,000 & 432 & 23,000 & 3.2 & 0.5 & 4 \\
$\begin{array}{l}\text { Yayınevlerinin } \\
\text { paketleri }\end{array}$ & 304,000 & 134 & 134,000 & 2.3 & 0.5 & 3 \\
$\begin{array}{l}\text { Aracı şirketlerin } \\
\text { paketleri }\end{array}$ & 27,000 & 60 & 20,000 & 1.4 & 0.5 & 2 \\
\hline Toplam & $\mathbf{4 0 4 , 0 0 0}$ & $\mathbf{1 4 7}$ & $\mathbf{1 7 7 , 0 0 0}$ & $\mathbf{2 . 3}$ & $\mathbf{0 . 5}$ & $\mathbf{2 . 8}$ \\
\hline $\begin{array}{l}\text { Basılı dergiler } \\
\text { Yeni dergiler }\end{array}$ & $\mathbf{3 8 , 0 0 0}$ & 100 & 15,000 & 2.3 & 6 & 8.5 \\
Ciltlenmiş dergiler & -- & -- & 8,800 & -- & 30 & 30 \\
\hline Toplam & $\mathbf{3 8 , 0 0 0}$ & $\mathbf{1 0 0}$ & $\mathbf{2 4 , 0 0 0}$ & $\mathbf{2 . 3}$ & $\mathbf{1 5}$ & $\mathbf{1 7 . 5}$ \\
\hline
\end{tabular}

Kaynak: (Montgomery ve King, 2002; Cox, 2003, s. 87).

Drexel projesinde tek tek abone olunan elektronik dergilerin CPR'si yaklaşık 4 dolar olarak belirlenmiştir. Basılı dergilerin yeni sayılarının makalelerine yaklaşık 8 dolar harcanırken bu dergilerin ciltlenmiş sayılarının makalelerine 30 dolar harcanmıştır. Toplam harcamaları hesapladığımız zaman elektronik dergilerde her kullanımın maliyeti 2,8 dolar, basılı dergilerde 17,5 dolar olarak belirlenmiştir (Bkz. Tablo 1). 


\section{Temel Bilimler İleri Araştırmalar Enstitüsü (TBIAE) Kütüphanesi}

17 Haziran 1994 tarihinde resmi olarak açılan İran Temel Bilimler Ileri Araştırmalar Enstitüsü (TBIAE, Merkeze Tehsiylate Tekmili der Olume Paye = Institute for Advanced Studies in Basic Sciences)'nün amacı temel bilimler konusunda, lisans üstü eğitim vermek ve bu konularda araştırma yapmaktır (TBIAE, 1997, s. 4). TBIAE bünyesinde altı fakülte (fizik, matematik, kimya, biyoloji, jeoloji ve bilgisayar) planlanmıştır. Kuruluşundan bu yana fizik, matematik ve kimya fakülteleri açılmış. 2003-2004 öğretim yılında da bilgisayar bölümünün açılması kararlaştırılmıştır. Enstitüye İan'da ilk olarak lise mezunlarından doğrudan doktora eğitim için öğrenci alınmıştır. Günümüzde (20 Nisan 2004 tarihi itibariyle) TBIAE'de toplam 206 öğrenci öğrenim görmektedir. Bu öğrencilerin 127'si yüksek lisans, 79'u doktora düzeyindedir.

Enstitü kütüphanesi için 1994-2001 yılları arasında başlangıç olarak "çekirdek koleksiyon" (core collection) oluşturmak amacıyla yaklaşık 3 milyon dolar* harcanmıştır. Her yıl dergilerin artan fiyatları ve kütüphanenin değişmez bütçesi (dolara göre) dergilerin sayısını azaltmaktadır. Dergilerin ciltlenmesi, kataloglanması, depolanması ve erişimi kütüphanenin en önemli sorununu teşkil etmektedir. Kütüphane halen ciddi bir para ve yer sıkıntısı ile karşı karşıyadır.

TBIAE Kütüphanesi koleksiyonu kitap, dergi, tez vb. kaynaklardan oluşmaktadır. Kütüphane 1993'de 1500 kitap ve 70 dergiyle işe başlamış, bu sayı 1995'te 3200 kitap ve 230 dergiye yükselmiştir. Kütüphanede 30 Eylül 2002 tarihi itibariyle toplam 29.535 adet kaynak vardır. Kaynakların \%39,1'i ciltlenmiş dergiler, \%34,3'ü yabancı kitaplar, \%13,6'sı Farsça kitaplar ve \%13'ü diğer kaynaklardan oluşmaktadır (TBIAE, 1999, s. 34; 2003, s. 35).

Üniversite kütüphanelerinde koleksiyon konusunda genellikle kesin sayılar verilmesi pek doğru olmaz. Çünkü önemli olan koleksiyonun büyüklüğü değil, gereksinmelere cevap verme özelliğidir. Ancak standartlara göre, yeni kurulan temel bilim eğitim merkezleri ve üniversitelerde çekirdek koleksiyon için en az 32.000 kaynaklı bir koleksiyon bulunması önerilmektedir (Taavoni, 2002, s. 19). Değişik çalışmalarda bütçenin \%20 ile \%30'u koleksiyon geliş-

* Araştırmada bütün harcamalar ABD Doları olarak hesaplanmıştır. Aksi belirtilmedikçe metinde geçen "dolar" sözcüğünden ABD Doları anlaşılmalıdır. 
tirme harcamalarına aittir (Evans, 1998, s. 373; Fisher ve Leonard, 1997, s. 213). İran'daki üniversite kütüphaneleri standartlarına göre TBİAE Kütüphanesinde bulunması gereken kaynak sayısı 65.200 adet olmalıdır (Taavoni, 2002, s. 18). Yani TBIAE Kütüphanesi standardın sadece \%45,3'üne ulaşabilmiştir.

Kütüphanenin bütçesi 2002'de 389.840 dolar olarak hesaplanmıştır. Tablo 2'de 2002 yılında TBİAE Kütüphane bütçesinin harcama kalemlerine göre dağılımı gösterilmiştir. 2002'de koleksiyon geliştirme için ayrılan pay 283.000 dolardır; yani bütçesinin ortalama \%73'ü koleksiyon geliştirmeye harcanmaktadır. Öğrenci başına düşen koleksiyon geliştirme bütçesi 2002'de ortalama 1695 dolardır (TBİAE Kütüphanesi, 2003, s. 3). Bu miktar birçok üniversite kütüphanesinin koleksiyon geliştirme harcamalarına göre daha yüksektir.

\section{Tablo 2. 2002 yılında TBİAE Kütüphanesinin Bütçe Dağılımı}

\begin{tabular}{lcc}
\hline Harcamalar & Harcama miktarı (\$) & Toplam bütçeye oranı \% \\
\hline \hline Koleksiyon geliştirme & 283.000 & 72,6 \\
İşçilik maliyetleri & 41.120 & 10,6 \\
Hazırlama & 35.662 & 9,1 \\
Teçhizat & 12.500 & 3,2 \\
Hizmetler & 11.423 & 2,9 \\
Bina giderleri & 4.610 & 1,2 \\
Çeşitli harcamalar & 1.525 & 0,4 \\
\hline Toplam & $\mathbf{3 8 9 . 8 4 0}$ & $\mathbf{1 0 0 , 0}$ \\
\hline
\end{tabular}

Standartlara göre İran'da dergi satın almak için ayrılan pay, üniversitelerin özelliklerine (programlar, öğrenci sayısı vb.) göre kütüphane bütçesinin \%30 ile \%70 arasında değişmektedir (Taavoni, 2002, s. 45). Ancak TBIAE Kütüphanesi bütçesinin büyük bir bölümü dergi aboneliklerine harcanmaktadır (Bkz. Tablo 3). 2000 ile 2002 yılları arasında koleksiyon geliştirme bütçesinin ortalama \%86,2'si dergiler, \%12,8'i kitaplar, \%1'i CD, film, kasetler ve başka kaynaklar için harcanmıştır (TBİAE Kütüphanesi, 2001, s. 3; 2002, s. 3). 
Tablo 3. TBİAE Kütüphane Bütçesinin Satın Alınan Kaynak Türüne Göre Dağılımı (2000-2002)

\begin{tabular}{lccccccc}
\hline YIl & Kitaplar (\$) & $\%$ & Dergiler $(\$)$ & $\%$ & Diğer $(\$)$ & $\%$ & Toplam (\$) \\
\hline 2000 & 45,100 & 20 & 181,320 & 79 & 3,580 & 1 & 230,000 \\
2001 & 30,200 & 12 & 213,900 & 87 & 1,900 & 1 & 246,000 \\
2002 & 22,250 & 7 & 258,920 & 92 & 1,830 & 1 & 283,000 \\
\hline Ortalama & $\mathbf{3 2 , 5 1 7}$ & $\mathbf{1 3}$ & $\mathbf{2 1 8 , 0 4 6}$ & $\mathbf{8 6}$ & $\mathbf{2 , 4 3 7}$ & $\mathbf{1}$ & $\mathbf{2 5 3 , 0 0 0}$ \\
\hline
\end{tabular}

TBIAAE Kütüphanesinde 2002'de basılı dergilere abone olmak için toplam 258.920 dolar harcanmıştır. Bu kaynaklara yapılan ödemeler ve işletme harcamalarını da eklediğimiz takdirde, TBIAE Kütüphanesi 2002'de basılı dergilere toplam 349.242 dolar yatırmıştır. Abone olunan dergilerin fiyatlarında 2000 ile 2002 arasında ortalama \%21'lik bir artış (yıllık artış yaklaşık \%10,5) vardır. Aynı dönemde bu kütüphanenin bütçesinden ayrılan pay sadece \%15 (yıllık artış yaklaşık \%7,5) artmıştır. Başka bir deyişle mevcut bütçeyle aynı düzeyde kaynak satın almak imkânsızdır. Bu nedenle TBIAE Kütüphanesinde birçok derginin aboneliği iptal edilmek zorundadır.

TBİAE Kütüphanesi 1993'ten 2001 tarihine kadar süren sekiz yıllık süre içinde dört kez yer değiştirmiştir. 1993'te Kütüphanenin kullanım alanı 30 m $^{2}$ iken 1994'te 80 m'ye, 1996'da 250 m²ye, 1998'de 290 m'ye yükselmiştir. Kütüphane son olarak Nisan 2001 tarihinde Fizik Fakültesinin yeni binasının giriş katına taşınmıştır. Kütüphane 480 metre karelik bir alan üzerinde kurulmuştur (TBIAE, 1999, s. 34; 2002, s. 35). Kütüphanenin sınırlı yer kapasitesini göz önüne alacak olursak, gelecek yıllar içinde herhangi bir genişlemenin olanaksız olduğu görülür. Merkezi Kütüphanenin orijinal binasının toplam alanı $4300 \mathrm{~m}^{2}$ olarak planlanmıştır. Şu anda kütüphane alanının $185 \mathrm{~m}^{2}$ 'si kitap deposuna aittir. Ciltlenmiş dergilerin depolanmasında ise $170 \mathrm{~m}^{2}$ kullanılmaktadır (TBIAE Kütüphanesi, 2001, s. 2).

\section{Araştırmanın Yöntemi}

Bu çalışmada 2002 yılında TBIAE Kütüphanesinde abone olunan 134 adet yabancı basılı derginin yanı sıra, geçmiş yıllarda bütçe sıkıntılar nedeniyle abonelikleri iptal edilen 21 önemli dergi de değerlendirilmiştir. Bu nedenle 
toplam olarak 155 tane dergi incelenmiştir. Araştırmada bu dergilerin basılı ve elektronik sürümlerinin abonelik ücretleri, gerekli teçhizatın fiyatları, bu kaynakları depolamak için gereken harcamalar ve genel bilgiler betimleme yöntemiyle elde edilmiştir.

Dergilerin listesi belirlendikten sonra çalışma dört aşamada gerçekleşmiştir: 1) Dergilerin basılı ve elektronik sürümlerinin fiyatları ile ilgili bilgilerin toplanması ve karşılaştırılması. 2) Dergilerin denetimi ile ilgili harcamaların hesaplanması. 3) Depolamak için gerekli tesisler ve teçhizat harcamalarının hesaplanması. 4) Kullanıcılara verilen hizmetler için yapılan harcamalar. 5) Bu işlemler ve hizmetler için gerekli işçilik maliyetlerinin hesaplanması.

TBIAE Kütüphanesinde abone olunan dergilerin elektronik sürümlerinin fiyatlarını incelemek için ilk önce yayınevlerine göre bir sınıflama yapılmıştır. TBIAE'nin üçten fazla dergisine abone olduğu yayınevleri saptanmış ve çalışmamızda yayınevleriyle ilgili incelemelerde öncelik bunlara verilmiştir. Daha sonra TBIAE Kütüphanesinde abone olunan dergilerin hangilerine elektronik olarak ulaşılabileceği saptanmıştır.

Ikinci aşamada basılı ve elektronik dergilerin sipariş ve doğrulama işlemlerinin maliyeti ve posta harcamaları belirlenmiştir. Her sayıya yapılan denetim harcamalarını hesaplamak amacıyla öncelikle bu konuda bütün işlemler belirlenmiştir. Ancak yine de tek bir dergi sayısı için yapılan denetim giderlerini hesaplamak hemen hemen imkânsızdır.

Dergilerin depolama maliyetleri üç grup olarak incelenmiştir: ciltlenmemiş basılı dergiler (yeni sayılar), ciltlenmiş basılı dergiler (eski sayılar) ve elektronik dergiler. Bu aşamada basılı dergilerin elektronik sürümlerine abone olunduğu takdirde gerekli rafların sayısı hesaplanmış ve toplam alan belirlenmiştir. Ciltlenmiş dergilerin depolama maliyeti, ciltleme maliyeti ve ciltlenmiş dergileri depolamak için gerekli teçhizatın maliyetinden oluşmaktadır. Elektronik dergilerin depolama maliyeti, özellikle kampus ağının oluşturulması, bilgisayar donanımları (sunucu ve iş istasyonları), bilgisayar sisteminin muhafazası, bilgisayar yazılımının satın alınması veya güncellenmesi için yapılan harcamalar olarak hesaplanmıştır. Bilgisayar teçhizatıyla ilgili harcamaları hesaplarken mevcut teçhizat da göz önüne alınmıştır. 
Kullanıcılara verilen hizmetlerin maliyetleri fotokopi harcamalarından ve gerekli teçhizatın maliyetinden oluşmaktadır. TBIAE Kütüphanesinde fotokopi çekme hizmetinin maliyetini hesaplamak için bu bölümün aylık raporlarından yararlanılmış ve 2002'de dergilerden çekilen fotokopi sayısı istek fişlerinden belirlenmiştir.

İşçilik maliyetlerini hesaplamak amacıyla, süreli yayınlar ile ilgili çalışan personelin sarf ettiği zaman üzerinde bir inceleme yapılmıştır. Bu hesaplama personelin dergilerin denetimi ve düzenlenmesi (ciltlemeye hazırlamak, kontrol etmek ve ciltlenmiş dergileri kayıt defterine yazmak vb.) ve fotokopi için sarf ettiği zamanların değerini kapsamaktadır.

\section{Bulgular}

\section{Dergilerin Fiyatları}

2002'de TBIAE Kütüphanesinde abone olunan dergilerin basılı ve elektronik sürümlerine yapılan harcamaların karşılaştırılması için ilk önce bu dergilerin abonelik ücretleri hesaplanmıştır. Fiyatlandırmada kullanılan değişik modeller nedeniyle dergilerin basılı ve elektronik fiyatlarının yayınevlerine göre ayrı ayrı karşılaştırılması gerekmektedir. Abone olunan yayınların büyük bir kısmının belli yayınevleri üzerinde yoğunlaştığı görülmüştür. Üç den fazla dergisine abone olunan yayınevlerine öncelik verilmiştir. Üç dergiden az aboneliği olan yayınevleri de bir grup halinde incelenmiştir (Bkz. Tablo 4).

TBİAE Kütüphanesi 2002'de Elsevier Yayınevinin 27 dergisine abone olmuş ve bu dergilerin basılı sürümlerinin abonelik ücreti olarak toplam 112.603 dolar ödemiştir. ${ }^{1}$ Aynı dönemde bu kütüphane Springer \& Birkhäuser tarafından yayınlanan 18 dergiye abone olmuştur. Bu iki yayınevi tarafından yayınlanan dergilerin elektronik sürümlerine sadece konsorsiyum aracılığıyla erişme imkânı vardır. Ancak Springer tarafından yayınlanan Zentralblatt MATH adlı derginin elektronik sürümüne tek bir başlık olarak abonelik mümkündür. Bu derginin elektronik sürümünün ücreti, basılı olan sürümüne göre 923 dolar ucuzdur. İran'da Elsevier ve Springer yayınevlerinin dergile-

\footnotetext{
${ }^{1}$ Yayınevlerine ödenen abonelik ücretleri 2002 yılına ait TBIAE faturalarından elde edilmiştir.
} 
rinden yararlanmak için Ros-Net Sistemi aracılığıyla Bilim ve Teknoloji Bakanlığı ile bu yayınevlerinin arasında 2002'de bir anlaşma imzalanmıştır. ${ }^{2}$ Bu anlaşmaya göre 21 büyük üniversite ve kuruluşa, söz konusu yayınevlerine ait ScienceDirect ve LINK veri tabanlarına üç yıl süreyle erişim sağlanmıştır. TBIAE Kütüphanesinin bu dergilerin aboneliklerini kesmeden, BakanIığın desteğiyle bu yayınevlerinin dergilerine elektronik olarak Teorik Fizik ve Matematik Araştırma Enstitüsü (IPM) ${ }^{3}$ aracılığıyla erişme imkânı vardır.

TBIAE Kütüphanesi 2002'de Amerikan Kimya Kurumu'nca (ACS) yayınlanan dergilerden 15 tanesine ve Amerikan Matematik Derneği (AMS) tarafından yayınlanan dergilerin 12 tanesine abone olmuştur. Bu dergilerin dört tanesi sadece basılı olarak yayınlanmakta ve abone olunan dergilerden ikisinin elektronik sürümleri bedava olarak sunulmaktadır. Ancak elektronik sürümleri bedava olan dergilerin sayısı 2003'de beşe yükselmiştir. TBIAE Kütüphanesi, Amerikan Fizik Enstitüsü (AIP)'nün on, Amerikan Fizik Derneği'nin (APS) dokuz, Academic Press'in altı, Amerikan Optik Derneği'nin (OSA) beş, ve Kraliyet Kimya Derneği (RSC)'nin yedi dergisine abone olmuştur. Sözü geçen yedi yayınevi tarafından yayınlanan dergilerin basılı ve elektronik sürümlerinin abonelik ücretleri arasındaki fark 26.868 dolar olarak saptanmıştır (Bkz. Tablo 4).

TBIAE Kütüphanesi 2002'de Fizik Enstitüsü (IOP)'nün 11 dergisine, World Scientific'in 10, ve Wiley'nin yayınladığı dergilerin beş tanesine abone olmuştur. Bu dergilerin abonelik ücreti toplam 60.333 dolar olarak hesaplanmıştır. Bu üç yayınevinin dergileri hem basılı hem de elektronik olarak sunulmaktadır. Sadece elektronik sürümlere abone olmak imkânı olmadığından karşılaştırma yapılamamıştır (Bkz. Tablo 4).

\footnotetext{
2 Ros-Net sistemi Şubat 1998'de Bilim ve Teknoloji Bakanlığının desteğiyle Ros şirketi tarafından kuruldu. Bu sistemin amacı üniversite kütüphanelerinin elektronik kaynakları satın alması için bir konsorsiyum oluşturmaktır. Bu sistemle halen birçok büyük yayınevi ve aracı şirketin kaynaklarına ve veri tabanlarına erişim sağlanmaktadır. (örneğin, Elsevier, Bowker, UMI, ISI, Ebsco, Dialog, SilverPlatter, vb.). <http://www.rose-net.ac.ir>

3 Institute for Studies in Theoretical Physics and Mathematics (IPM); Bu kuruluş bir araştırma enstitüsü olarak fizik ve matematik konusunda Iran'ın en önemli kaynaklarına sahiptir. Bilim ve Teknoloji Bakanlığının kararına göre bu Bakanlığa bağlı olan enstitüler IPM'in bütün kaynaklarından yararlanmaktadır. Bu enstitüler içinde TBIAE'nin önemli bir yeri vardır.
} 
Sözü geçen yayınevlerinin dışında TBİAE Kütüphanesi çeşitli yayınevleri tarafından yayınlanan 20 dergiye de abone olmuştur. Bu dergilerin içinde ikisi sadece basılı ve üç dergi paralel olarak yayınlanmaktadır. 2002'de TBIAE Kütüphanesi tarafından diğer abone olunan 15 derginin basılı sürümlerine ödenen abonelik ücreti 21.487 dolardır. Söz konusu bu dergilerin elektronik sürümlerinin 2002'deki fiyatları 15.085 dolardır. Bu dergilerin basılı ve elektronik sürümlerinin aradaki fark 6402 dolar olarak saptanmıştır (Bkz. Tablo 4).

Karşılaştırma sonuçlarına göre TBIAE Kütüphanesinde 2002'de abone olunan dergiler içinde 10 tanesi sadece basılı olarak yayınlanmıştır ki, bu sayı TBIAE Kütüphanesi tarafından abone olunan dergilerin \%6,5'ini kapsamaktadır. Ayrıca incelenen dergiler içinde 29 tanesi basılı ve elektronik sürümleri birlikte (Fizik Enstitüsü $=11$, World Scientific $=10$, Wiley $=5$, diğer yayınevleri $=3$ ) abone olunan ve 43 tanesi (Elsevier $=27$ ve Springer $=16$ ) elektronik sürümlerine sadece konsorsiyum aracılığıyla erişme imkânı olan dergilerdir. Bu 72 derginin sadece elektronik sürümlerine abone olmak imkânsızdır. Bunlar abone olunan dergilerinin \%46,5'ini kapsamaktadır.

Academic Press'in ürettiği IDEAL veri tabanındaki yaklaşık 335 dergisinin elektronik sürümlerine 2003'den itibaren ScienceDirect üzerinden erişilebilmektedir. Buna göre temel bilimler alanlarındaki üç büyük ticari yayınevinin (Elsevier, Springer ve Academic Press) tüm elektronik dergilerinin 2002 yılına ait ve geriye dönük olmak üzere tam metin makalelerine Bilim Bakanlığı aracılığıyla ulaşıımaktadır. Bu üç yayınevine ödenen abonelik ücreti değişmemesine rağmen tam metinlerine erişilen dergilerin sayısı çoğalmaktadır. Bu durumda abone olunan basılı dergilerin yanı sıra 2115 yeni dergiye elektronik ortamda da erişme imkânı sağlanmaktadır. Söz konusu dergiler içinde 570 dergi TBIAE'deki eğitim programları ile ilgilidir. 
Tablo 4: Abone Olunan Dergilerin Basılı ve Elektronik Sürümleri Arasındaki Fiyat Farklııkları

\begin{tabular}{lcrrr}
\hline Yayınevleri & Dergi sayısı & Basılı (\$) & Elektronik (\$) & Fark (\$) \\
\hline Elsevier Science & 27 & 112,603 & 112,603 & ---- \\
Springer \& Birkhäuser & 18 & 38,290 & 37,367 & 923 \\
Amerikan Kimya Kurumu (ACS) & 15 & 30,133 & 24,256 & 5,877 \\
Amerikan Matematik Derneği (AMS) & 12 & 9,962 & 4,674 & 5,288 \\
Fizik Enstitüsü (IOP) & 11 & 31,658 & 31,658 & $-\cdots$ \\
Amerikan Fizik Enstitüsü (AIP) & 10 & 14,665 & 8.7 & 5,965 \\
World Scientific & 10 & 18,149 & 18,149 & ---- \\
Amerikan Fizik Derneği (APS) & 9 & 18,705 & 14,440 & 4,265 \\
Kraliyet Kimya Derneği (RCS) & 7 & 12,993 & 11,520 & 1,473 \\
Academic Pres & 6 & 12,652 & 11,103 & 1,549 \\
Wiley & 5 & 10,526 & 10,526 & ---- \\
Amerikan Optik Derneği (OSA) & 5 & 8,356 & 6,005 & 2,351 \\
Diğer yayınevleri & 20 & 21,487 & 15,085 & 6,402 \\
\hline Toplam & $\mathbf{1 5 5}$ & $\mathbf{3 4 6 , 1 4 4}$ & $\mathbf{3 1 2 , 0 5 1}$ & $\mathbf{3 4 , 0 9 3}$ \\
\hline
\end{tabular}

Bu Kütüphanede 2002'de abone olunan 73 dergi araştırmamızla ilgili hesaplamalarda kütüphanenin harcamalarının azalmasını etkilemektedir. Bu dergiler ikiye ayrılmaktadır. Birinci gruptaki dergilere basılı ve elektronik sürümleri ile birlikte abone olunmasının yanı sıra bu dergilerin sadece elektronik sürümlerine de abone olmak imkânı vardır. Bu dergilerin sayısı 29 tanedir ve tüm dergilerin \%18,7'sini kapsamaktadır. İkinci grupta yer alan 44 derginin basılı ve elektronik sürümleri ayrı olarak sunulmakta ve bunlar tüm dergilerin \%28,4'ünü kapsamaktadır. Bu dergilerin basılı sürümlerinin abonelik ücretleri 346.144 dolar ve elektronik sürümlerinin abonelik ücretleri 312.051 dolar olarak hesaplanmıştır. İki grubun arasındaki fark 34.093 dolardır (bkz. Tablo 5). Elektronik sürümlerin abonelik ücretleri basılı sürümlerden yaklaşık \%24,8 daha azdır. Bu miktarı bütün dergiler ile karşılaştırdığımız zaman dergilerin abonelik harcamalarında yaklaşık \%9,7 kadar bir azalmadan yararlanma imkânı vardır.

Sürümleri değiş̧en dergilerin abonelik ücretlerinden sağlanan tasarrufun yanı sıra TBIAE Kütüphanesinde abone olunan dergilerin sayısı da önemli bir miktarda artmaktadır. Kütüphane 10 basılı dergiye, 72 derginin basılı ve 
elektronik sürümlerine birlikte, 73 derginin sadece elektronik sürümlerine ve 2115 yeni elektronik dergiye abone olarak aslında toplam 2260 dergiye elektronik ortamda erişme imkânına kavuşacaktır $(72+73+2115+=2260)$. Söz konusu elektronik dergilerin içinde matematik, fizik, bilgisayar ve kimya ile ilgili 570 dergi bulunmaktadır. TBIAE Kütüphanesi 2002'de toplam 352.135 dolar ödeyerek 155 dergiye abone olarak ortalama her dergiye 2272 dolar ödenmiştir. Ancak bu kütüphane elektronik sürümlerden yararlanırsa her dergiye 140 dolar ödeyerek basılı ve elektronik ortamda toplam 2270 dergiye erişebilecektir.

\section{Denetim Harcamaları}

Dergilerin siparişi ile ilgili harcamalar, birkaç derginin sürümleri değiştiği takdirde azalmamaktadır. Ancak sadece elektronik dergilere abone olunduğu zaman, harcamalarda bir azalma söz konusu olabilir. Dergiler genellikle ABD ve Avrupa'dan postaya verildiğinden bu dergilerin yüksek posta harcamaları vardır. Kütüphane bu işlemler için dergi fiyatlarının \%8'i civarında bir ücret ödemektedir. TBIAE Kütüphanesi tarafından 2002'de Napoleon aracı şirketine ödenen miktar toplam 20.608 dolar olarak hesaplanmıştır. ${ }^{4}$ Çalışmamızla ilgili sürümleri değişen 73 derginin posta harcamaları için 2002'de Napoleon Şirketine ödenen miktar 11.007 dolar olarak saptanmıştır. Söz konusu dergilerin elektronik sürümlerini kullanıldığı takdirde TBIAE Kütüphanesi 11.007 dolar tasarruf sağlama olanağı elde edecektir.

Genel olarak İran'da üniversite kütüphanelerinde, kütüphane dışında bütün denetim işlemleri (örneğin, eksik sayı için istek yapmak, kargoları gümrükten almak ve kütüphaneye teslim etmek gibi) aracı şirketler tarafından yapılmaktadır. Kütüphaneler aracı şirketlere bu işlemler için bir miktar ücret ödemektedirler. Bu miktar dergilerin konularına, kütüphanenin bulunduğu yere, abone olunan dergilerin sayısına göre değişmektedir. TBIAE Kütüphanesi aracı şirketin işlemleri için dergi fiyatlarının \%7'si civarında bir ücret ödemektedir. Söz konusu dergilerin elektronik sürümlerini kullandığımız takdirde TBIAE Kütüphanesi 9.632 dolar tasarruf sağlama olanağı elde edecektir. Sonuç olarak sürümleri değişen dergilerin posta ve denetim işlemleri için araCı şirkete ödenen para 20.639 dolar azalmaktadır.

\footnotetext{
4 Napoleon aracı şirketine ödenen miktar 2002 yılına ait TBIAE faturalarından elde edilmiştir.
} 


\section{Arşivleme Harcamaları}

Dergilerin arşivleme maliyetleri üç grup halinde incelenmelidir:

A) Ciltlenmemiş basılı dergiler (yeni sayılar): Sürümleri değişen toplam 73 derginin yeni sayılarını hizmete sunmak için gerekli raf sayısı yaklaşık beş adet olarak hesaplanmıştır (her 15 dergiye bir raf). Kazanılan alan ise yaklaşık $5 \mathrm{~m}^{2}$ 'dir. Ancak dergilerin elektronik sürümlerine geçildiği takdirde boşaIan alana yeni bilgisayarlar ve yazıcılar yerleştirilebilir.

B) Ciltlenmiş basılı dergiler (eski sayılar): TBIAE Kütüphanesi 2002'de dergilerin ciltlenmesi için toplam 3967 dolar harcamıştır. Bu miktar dergileri taşıma ve kontrol etme giderlerini de kapsamaktadır. Ciltlenen dergi sayısı 1058 olduğuna göre her cilt için ödenen miktar ise 3,75 dolar olarak hesaplanmıştır. Sürümleri değişen 73 derginin ciltlenen sayısı toplam 455 adet olduğundan, TBIAE Kütüphanesi basılı dergiler yerine aynı dergilerin elektronik sürümlerine abone olduğu takdirde dergilerin ciltlemesinde toplam 1706 dolarlık bir tasarruf sağlayabilir. Ayrıca bu dergilerin depolanması için gerekli olan raflara ödenen miktar da 661 dolar olarak hesaplanmıştır.

C) Elektronik dergilerin arşivi: Elektronik dergilerden yararlanmak için gerekli teçhizatı belirlemek amacıyla TBİAE Bilgisayar Bölümü Başkanı ve Bilgisayar Laboratuvarı Başkanından yararlanılmıştır. İki uzman, kütüphanedeki mevcut teçhizatı inceledikten sonra gerekli teçhizatı belirlemişlerdir. Kütüphane internetten yararlanmak ve kullanıcılarının çoklu ortam kaynaklarına kütüphane içinde erişebilmeleri için yeterli sayıda bilgisayar, yazıcı ve diğer donanımı bulundurmaktadır. Geçmiş yıllarda kütüphaneye çeşitli teçhizat satın alınmıştır (Bkz. Tablo 5). Bu öneride TBİAE'deki sistemler ve teçhizat göz önüne alınmış ve yaklaşık fiyatlar belirlenmiştir. Bu hesaplamada bir sene içinde bilgisayar donanım ve yazılımının muhafazası, sistemin muhafazası, bilgisayar yazııımının satın alınması veya güncelleme harcamaları yer almaktadır. 
Tablo 5. Elektronik Dergilerin Arşivi İçin Gereken Teçhizat

\begin{tabular}{lccr}
\hline Teçhizat & Gereken sayı & Mevcut & Harcama (\$) \\
\hline Dosya ve web sunucusu & 1 & 1 & 13,700 \\
Bilgisayar & 10 & 6 & 5,200 \\
Yazılım & 3 & 2 & 2,700 \\
Hub-Switch & 1 & 1 & 1,850 \\
Yazıcı & 6 & 3 & 1,800 \\
Tarayıcı & 2 & 1 & 500 \\
CD yazar & 2 & 1 & 350 \\
\hline Toplam & & & $\mathbf{2 6 , 1 0 0}$ \\
\hline
\end{tabular}

Bu öneriye göre kütüphanedeki mevcut dosya ve web sunucusunun yükseltilmesi için 13.700 dolarlık bir yatırıma intiyaç vardır. Mevcut şartlarda Kütüphanede 10 bilgisayara gereksinim vardır. Eksik olan dört bilgisayarın maliyeti toplam 5200 dolardır. Internete bağlantı sayısını 24'e yükseltmek için yeni bir Hub-Switch (Cisco- 3Com "24 port") lazımdır. Bu yeni switch'in fiyatı ise 1850 dolar olarak hesaplanmıştır. Ayrıca kaynakları ve bilgileri kolayca arşivlemek ve kullanmak için başka bir yazılım programı gerekmektedir. Bu yazılımın hazırlanması ve bilgileri yükleme maliyeti de yaklaşık 2700 dolar tutmaktadır. Sözü geçen teçhizatın yanı sıra üç yazıcı, bir tarayıcı ve bir CD yazıcıya (toplam 2650 dolar) daha intiyaç vardır.

Dergilerin elektronik sürümlerini arşivlemek ve kullanıcılara hizmet vermek için ilk dönemde gerekli teçhizatın satın alınması için toplam 26.100 dolarlık bir yatırım gerekmektedir. Yani gerekli teçhizatın satın alınması için TBIAE Kütüphanesinin teçhizat satın alma bütçesinde ortalama \%209'luk bir artış gereklidir. Illk bakışta bu yatırımın miktarı yüksek gibi görülmektedir. Ancak daha sonraki yıllarda bu miktarda yatırıma gerek yoktur. Elektronik dergilerin arşivlenmesi ve verilen hizmetlere düşen teçhizat amortismanını hesaplamak için bu teçhizatın ömrü belirlenmelidir. Bu tür teçhizatın fiziksel ömrü yaklaşık beş yıldır (Lawrence, 2001, s. 547). Bilgisayar teçhizatının ömrü beş yıl civarında olduğuna göre bir yıl için \%20 amortisman oranı alınmıştır ve teçhizat giderleri her yıl için 5220 dolar olarak hesaplanmıştır. 


\section{Kullanıcı Hizmetleri}

TBIAE Kütüphanesinde dergilerden fotokopi çekmek bedava ve TBIAE mensuplarına sınırsızdır. Bu nedenle kütüphanede bu hizmetler için harcanan para yüksektir. TBIAE Kütüphanesi 2002'de fotokopi bölümünde kullanıcılara hizmet sunmak için toplam 8735 dolar harcamıştır. Bu giderler fotokopi makinelerinin bakım ve onarımı, kâğıt, elektronik ve sarf malzemeleri ve bu bölümde çalışan bir personelin yıllık ücretlerini kapsamaktadır. Bir sayfa fotokopi çekme maliyetini hesaplamak için bu bölümün raporlarından 2002'de dergilerden çekilen fotokopi sayısı istek fişlerinden belirlenmiştir. Bu istatistiklere göre 2002'de toplam 123.583 sayfa fotokopi çekilmiştir. Bu sayının içinde 75.952 sayfa basılı dergilerden çekilen makaleler de vardır (TBIAE Kütüphanesi, 2003, s. 3). Toplam gider miktarı 2002'de çekilen fotokopi sayısına bölündügü takdirde bir sayfaya harcanan miktar 0,07 dolar olarak saptanmıştır (Piyasada çekilen fotokopi ücretinin yaklaşık beş katıdır).

Sürümleri değişen dergilerin fotokopilerinden tasarruf sağlamak mümkündür. Ancak elektronik dergilerin makalelerinden alınan çıktı bu tasarrufu götürmektedir. Sürümleri değişen dergilerden çekilen fotokopi sayısı azalırken genellikle yazıcılardan alınan çıktı sayısı çoğalmaktadır. Makalelerin çıktıları çoğunlukla TBIAE mensuplarının odalarından veya Bilgisayar Laboratuarından alındığına göre kütüphanenin harcamaları önemli miktarda azalmaktadır. Çıktı sayısını daha önceden tahmin etmek zordur. Ancak çekilen fotokopi sayısına yakın olacağı tahmin edilebilir. Bunu kontrol etmenin en iyi yolu bir çeşit yazıcı sunucusu yazılımı almak ve yazıcıları personel kontrolündeki yerlerde tutmaktır. Her sayfa çıktının maliyeti 2001'de Bilgisayar Laboratuvarı tarafından 0,06 dolar hesaplanmıştır (bir sayfa fotokopiden 0,01 dolar daha ucuz).

İnternet aracılığıyla elektronik dergileri kullanmak için iletişim teknolojisinden de yararlanmak gerekmektedir. İran'da Bilim ve Teknoloji Bakanlığı tarafından internet kullanımını desteklemek amacıyla İran Bilimsel Araştırmalar Merkezi ile üniversiteler arasında anlaşmalar imzalanmaktadır. Bu anlaşmalara göre üniversiteler yıllık abonelik ücreti ödeyerek sınırsız olarak internetten yararlanabilir ve üniversitenin bütün mensupları evlerinden istediği kadar internet kullanabilirler. Bu olanak sayesinde TBİAE Kütüphanesi 256 Kbps (Kilo bit per second) hızındaki bir bağlantı ile internette sınırsız olarak erişebilmektedir. 
Işçilik maliyetleri

Kullanıcıların yeni sürümleri kullanmak için bu konuda eğitilmesi gerekmektedir. Yardımcı personelin eğitimi de vazgeçilmez öneme sahiptir. TBİAE'de her yılın başında yeni kayıt yaptıran öğrencilere internet teknolojisinden ve üniversitedeki ağdan yararlanmak için eğitim verilmektedir. Bu programların harcamaları Bilgisayar Bölümü tarafından ödendiğinden kütüphaneye bir maliyeti yoktur. Kütüphane personelinin çalıştıkları konularda yeni bilgi elde etmek ve son teknolojiler ile ilgili eğitim görmek için ayrılan payı 2002'de 850 dolar olarak hesaplanmıştır.

Kütüphanede çalışan iki uzman personelin zamanlarının yaklaşık \%37'si dergilerin denetimi ve düzenlenmesi ve \%12,7'si ciltleme işlemleri için (toplam \%49,7) kullanmaktadır. İki personelin 2002'de toplam doğrudan işçilik maliyeti (personel maaşı, sağlık sigortası ödemesi, ek gelir, ikramiye, giyim yardımı, vb.) yaklaşık 11.750 dolar olarak hesaplanmıştır. İki personelin dergilerin denetimi ve düzenlenmesi için sarf ettiği zamanın değeri de 5840 dolar olarak hesaplanmıştır (TBİAE Kütüphanesi, 2002, s. 4). Sürümleri değişen dergilerin yıllık sayıları toplam 945 adet olarak saptandığına göre bu sayı gelen bütün dergilerin yaklaşık \%47'sini kapsamaktadır. Söz konusu dergilerin elektronik sürümlerine abone olunduğu takdirde TBIAE Kütüphanesi personelinin artan zamanından yararlanma imkânı vardır ki, bu zamanın değeri 2744 dolar olarak hesaplanmıştır $(5840$ x 0,47 = 2744).

\section{Değerlendirme}

TBIAE Kütüphanesinde 2002'de abone olunan 155 dergiden 10 tanesi sadece basılı olarak yayınlanmaktadır. Aynı zamanda 72 basılı derginin elektronik sürümleri kütüphanenin harcamalarının azaltılmasında hiçbir etkisi yoktur. Söz konusu bu dergiler (toplam 82 dergi) abone olunan dergilerin toplam $\% 53$ 'ünü kapsamaktadır.

TBİAE Kütüphanesinde 2002'de abone olunan 73 basılı derginin yerine bu dergilerin elektronik sürümlerine abone olunduğu takdirde, dergilerin abonelik ücretlerinde düşüşe neden olacaktır. Sürümleri değişen dergilerin toplam basılı abonelik ücretleri 137.593 dolar, bu dergilerin elektronik abonelik ücretleri ise 103.500 dolardır. Yani abone olunan 73 derginin elektronik sürümlerinin abonelik ücretleri basılı sürümlerininkinden 34.093 dolar daha azdır (Bkz. Tablo 6). Bu rakam dergi aboneliklerinde toplam \%10'luk tasarruf anlamına gelmektedir. Elektronik dergilerin abonelik ücretlerinden sağlanan 
bu tasarruf ile birlikte TBİAE Kütüphanesi 2002'de abone olunan 155 derginin yanı sıra toplam 2115 yeni dergiye daha elektronik ortamda erişme imkânına kavuşacaktır. Bu elektronik dergilerin içinde matematik, fizik, bilgisayar ve kimya ile ilgili 570 dergi de bulunmaktadır.

Araştırmanın sonuçlarına göre elektronik dergilerin tek abonelikleri veya yayınevleri ve aracı şirketlerin elektronik dergi paketlerinin sipariş ve doğrulama işlemleri basılı dergilerin siparişlerine çok benzemektedir. Ancak sürümleri değişen dergilerin denetiminde önemli miktarda azalma söz konusudur. TBIAE Kütüphanesinin 2002 bütçesinin ortalama \%9,1'i kaynakların hazırlanması için harcamıştır. Aracı şirkete dergilerin denetimi için 18.080 dolar, posta harcamaları için ise 20.608 dolar ödenmiştir (toplam 38.688 dolar). TBIAE Kütüphanesi basılı dergilerin yerine elektronik sürümlere abone olduğu takdirde dergilerin posta harcamaları ve denetiminde toplam 20.639 (11.007+9632) dolarlık bir tasarruftan yararlanabilir. Yani elektronik sürümlerde kaynakların hazırlama giderleri için ortalama \%53 oranında tasarruf sağlanması söz konusudur (bkz. Tablo 6). Ayrıca dergilerin ciltlenmesi için ödenen miktarda (\%43) ve depolamak için kullanılan alanın maliyeti ve yıllık giderlerinde (\%45) azalma vardır ve dergilerin arşivleme harcamalarında da tasarrufa gidilebilmektedir. Dergilerin ciltlenmesi için ödenen miktarda 1706 dolarlık, bu dergilerin depolanmasında kullanılan raflar için de 661 dolarlıkta tasarruf sağlanmaktadır.

Tablo 6. TBIAE Kütüphanesinde Basılı Dergilerin Yerine Elektronik Sürümlere Abone Olduğu Takdirde Yapılması Gereken Harcamalar

\begin{tabular}{lrrrc}
\hline Harcamalar & $\begin{array}{r}\text { Basılı ortamda } \\
(\$)\end{array}$ & $\begin{array}{r}\text { Elektronik } \\
\text { ortamda }(\$)\end{array}$ & Değişik (\$) & $\%$ \\
\hline Abonelik ücretleri & 349,242 & 315,149 & $-34,093$ & -10 \\
Işçilik maliyetleri & 41,080 & 38,376 & $-2,744$ & -7 \\
Posta harcamaları & 20,608 & 9,601 & $-11,007$ & -53 \\
Aracı şirkete ödenen & 18,080 & 8,448 & $-9,632$ & -53 \\
Teçhizat & 12,500 & 17,720 & 5,220 & 42 \\
Ciltleme harcamaları & 3,967 & 2,261 & $-1,706$ & -43 \\
Depolama harcamaları & 1,470 & 809 & -661 & -45 \\
\hline Toplam tasarruf & $\mathbf{4 4 6 , 9 8 7}$ & $\mathbf{3 9 2 , 3 6 4}$ & $\mathbf{- 5 4 , 6 2 3}$ & $-\mathbf{- 1 3}$ \\
\hline
\end{tabular}


TBİAE Kütüphanesindeki özelliklere göre sürümleri değişen dergilerin bazı harcamalarında önemli bir değişiklik yoktur. Bu harcamalar şunlardır: Kullanıcı hizmetleri (fotokopi, çıktı), iletişim ve eğitim. Kullanıcılara verilen hizmetlerin maliyetleri teçhizat harcamaları dışında büyük bir değişiklik göstermemektedir. Çekilen fotokopi harcamaları aşağı yukarı çıktı harcamalarıyla aynıdır. Yeni teknolojilerden yararlanmak için verilen eğitim de kütüphane harcamalarında pek bir değişiklik yaratmamaktadır.

\section{Sonuç}

TBIAE Kütüphanesi 2002'de abone olunan basılı dergilerin yerine elektronik dergilere abone olsaydı harcamaların 446.987 dolardan 392.364 dolara düşmesi mümkündü. Yani, TBİAE Kütüphanesinde basılı dergiler yerine elektronik dergilere abone olunursa harcamalarda 54.623 dolar bir tasarruf sağlanabilir. Bu rakam TBIAE Kütüphanesinde dergi aboneliklerine yapılan harcamalarda yaklaşık \%10 tasarruf edilebileceği anlamına gelmektedir. Öte yandan elektronik dergilere abone olunduğu takdirde TBIAE Kütüphanesi toplam koleksiyon geliştirme harcamalarında (dergi abonelikleri, arşivleme, denetim, vb.) yaklaşık \%13'lük bir tasarruf sağlayabilecektir. Bu nedenle TBIAE Kütüphanesi karşı karşıya kaldığı ekonomik sorunların çözümü için en kısa zamanda basılı dergilerin yerine bu dergilerin elektronik sürümlerine abone olmak zorundadır.

Araştırmamızdan elde edilen sonuçlar doğrultusunda önerilerimiz şunlardır:

- Kütüphanenin sınırlı yer kapasitesini göz önüne alarak para ve yer sıkıntısını ortadan kaldırmak için TBİAE Kütüphanesi en kısa zamanda basılı dergilerin yerine elektronik dergilere abone olmalıdır. Basılı dergilere abone olmak yerine bu kaynakların elektronik kopyalarına erişim sağlamak ve kütüphanenin koleksiyon geliştirme politikalarını gözden geçirmek gerekmektedir.

- TBIAE Kütüphanesi az kullanılan basılı dergilere abone olmak yerine bu dergilerin elektronik sürümlerini yayınevlerinden sağlamalı ya da ticari elektronik belge sağlama şirketlerinin hizmetlerinden yararlanmalıdır. Kütüphane aynı zamanda yayınevlerinin "gördüğün kadar öde" (pay-per-view) modelinden de yararlanmalıdır.

-TBIAE Kütüphanesi elektronik dergileri hizmete sunmak, internetten daha verimli yararlanmak için iletişim alt yapısını geliştirmeli ve yeni sunucuları devreye sokmalıdır. 
-TBIAE Kütüphanesi elektronik dergileri kolayca arşivlemek ve kullanmak için gerekli yazılım ve donanım sağlamalıdır. Bu yazılımların hazırlanmasında ve aynı zamanda Farsça dilindeki alfabe sorunlarının çözümünde başka üniversite kütüphanelerinin çalışmalarından yararlanmak gerekmektedir.

-TBIAE Kütüphanesi basılı ortamdan elektronik ortama tam olarak geçiş için hazır olmalıdır. Kütüphane kullanıcılarına elektronik kaynaklardan yararlanmak için yardım etmelidir. Kütüphanede çalışan personele ve öğrencilere bu konuda eğitim vermelidir.

-Basılı ve elektronik dergilerden belge sağlamanın maliyet analizi ile ilgili yeni çalışmalar yapılmalıdır. Bu çalışmalarda dergilerden sağlanan/indirilen makalelerin birim maliyetleri, alt yapı, denetim ve amortisman giderleri de göz önüne olarak hesaplanmalıdır.

\section{Kaynakça}

Afzali, M. (2003). Elektronik bilgi kaynaklarının üniversite kütüphanelerine ekonomik etkisi: Iran Temel Bilimler Ileri Araştırmalar Enstitüsü örneği. Yayımlanmamış yüksek lisans tezi, Hacettepe Üniversitesi, Ankara.

Cox, J. (2003). Value for money in electronic journals: a survey of the early evidence and some preliminary conclusions. Serials Review 29(2), 83-88.

Çakın, I. (1998) Üniversitelerimizin bilgiye erişim ortamları: Genel değerlendirme. Hacettepe Üniversitesi Edebiyat Fakültesi Dergisi (Cumhuriyetimizin 75. Yılı Özel Sayısı), 37-67.

Evans, E. (1998). Mudiriyet teknologi berai ketabkhaneha [Kütüphaneler için teknoloji yönetimi]. Farsçaya Çeviren Fereşte Nasery. Mashhad: Astan Quds Razavi.

Fisher, W. ve Leonard, B.G. (1997). Budgeting for information resources: Current trends and future direction. G.E. Gorman, Ruth H. Miller (Ed.). Collection Management for the 21st Century: A handbook for librarians içinde (ss. 207-217). London: Greenwood Press. 
Gadd, E. (1998). Comparing paper and electronic short loan collections. Library Management, 19 (5), 311-317.

Holmström, J. (2004). The cost per article reading of open access articles. D-Lib Magazine. 10 (1) 13 Şubat 2004 tarihinde http://dlib.org/january04/ holmstrom/01holmstrom.html adresinden erişildi.

Kiernan, V. (1998). Paying by the article: Libraries test a new model for scholarly journals. The Chronicle of Higher Education, 14 August, A21-A22. 7 Kasım 2003 tarihinde http://www.lib.umich.edu/retired/ peak/chronicle.htm adresinden erişildi.

Lawrence, S. (2001). Life cycle cost of library collections: Creation of effective performance and cost metrics for library resources. College \& Research Libraries, 62 (6), 541-553.

Montgomery, C.H. (2000). Measuring the impact of an electronic journal collection on library costs: A framework and preliminary observations. $D$ Lib Magazine, 6 (10). 17 Aralık 2003 tarihinde http://www.dlib.org/dlib/ october00/ montgomery/10montgomery.html adresinden erişildi.

Montgomery, C.H. ve Bielec, J. A. (2000). The economic impact of an electronic journal collection in an academic library. 25 Aralık 2003 tarihinde http://www.library.drexel.edu/ facts/staff/dean/LisbonWireless.pdf adresinden erişildi.

Montgomery, C.H. ve King D.W. (2002) Comparing library and user related costs of print and electronic journal collections: A first step towards a comprehensive analysis. D-Lib Magazine, 8 (10). 9 Kasım 2003 tarihinde http://www.dlib.org/dlib/october02/montgomery/10montgomery.html adresinden erişildi.

Montgomery, C.H. ve King D.W. (2003) An "all" electronic journal collection in a university library: Two years later. ACRL Eleventh National Conference April 10-13, 2003, Charlotte, North Carolina 8 Şubat 2004 tarihinde http://www.ala.org/Cotent/NavigationMenu/ACRL/Event_and_ Conferences/hansen.pdf adresinden erişildi. 
Montgomery, C.H. ve Sparks, J. (2000). Framework for assessing the impact of an electronic journal collection on library costs and staffing patterns. 27 Kasım 2003 tarihinde http://www.si.umich.edu/PEAK-2000/ montgomery.pdf adresinden erişildi.

Obst, O. (2003). Patterns and costs of printed and online journal usage. Health Information and Libraries Journal, 20, 22-32.

Odlyzko, A.M. (1999). Competition and cooperation: Libraries and publishers in the transition to electronic scholarly journals. Journal of Electronic Publishing, 4 (4). 9 Kasım 2003 tarihinde http://www.press.umich.edu/ jep/0404/odlyzko0404.html adresinden erişildi.

Schmidt, K. (1999). The Association for College and Research Library Conference: A report. Library Collections, Acquisitions, and Technical Services, 23, 493-501.

Stange, K. (1999). Electronic journals in Swedish academic institutions : A usage of project MUSE and IDEAL full-text databases. 17 Ekim 2003 tarihinde http:/www.bibks.uu.se adresinden erişildi.

Taavoni, S. (2002). Standarthaı Ketabhaneha-i Daneşgah-i İan. [İran Üniversite Kütüphanelerinin standartları]. Tehran: National Library of the Islamic Republic of Iran.

TBIAE. (1997). Gozareş salıyane fealyethai Merkeze Tehsiyate Tekmili der Olume Paye, 1375. [Temel Bilimler Illeri Araştırmalar Enstitüsü'nün yıllık raporu 1996]. (Yayımlanmamış rapor). Zancan.

TBIAE. (1999). Gozareş salıyane fealyethai Merkeze Tehsiyate Tekmili der Olume Paye, 1377. [Temel Bilimler İleri Araştırmalar Enstitüsü'nün yıllık raporu 1998 ]. (Yayımlanmamış rapor). Zancan.

TBIAE. (2002). Gozareş salıyane fealyethai Merkeze Tehsiyate Tekmili der Olume Paye, 1380. [Temel Bilimler Illeri Araştırmalar Enstitüsü’nün yıllık raporu, 2001]. (Yayımlanmamış rapor). Zancan.

TBIAE. (2003). Gozareş salıyane fealyethai Merkeze Tehsiyate Tekmili der Olume Paye, 1381. [Temel Bilimler İleri Araştırmalar Enstitüsü'nün yıllık raporu, 2002]. (Yayımlanmamış rapor). Zancan. 
TBIAE Kütüphanesi. (2001). Gozareş salıyane ketabkhane, 1397 [Kütüphanenin yıllık raporu, 2000]. (Yayımlanmamış rapor). Zancan.

TBIAE Kütüphanesi. (2002). Gozareş salıyane ketabkhane, 1380 [Kütüphanenin yıllık raporu, 2001]. (Yayımlanmamış rapor). Zancan.

TBIAE Kütüphanesi. (2003). Gozareş salıyane ketabkhane, 1381 [Kütüphanenin yıllık raporu, 2002]. (Yayımlanmamış rapor). Zancan.

Tinerella, V. P. (1999). The crisis in scholarly publishing and the role of the academic library. Katharine Sharp Review, 8. 17 Kasım 2003 tarihinde http://www.lis.uiuc.edu/review/8/tinerella.html adresinden erişildi. 